\title{
The changing migration patterns of the 65+ population in Australia, 1976-2016
}

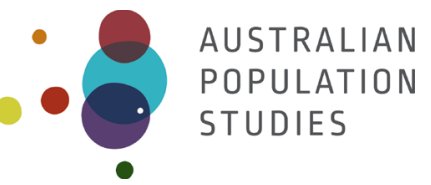

\author{
Rosabella Borsellino* The University of Queensland \\ * Email: rosabella.borsellino@uqconnect.edu.au. Address: Queensland Centre for Population \\ Research, School of Earth and Environmental Sciences, Chamberlain Building, The University of \\ Queensland, St Lucia, Qld 4072, Australia.
}

Paper received 11 February 2020; accepted 20 March 2020; published 25 May 2020.

\begin{abstract}
Background

The demand for amenity, health and aged care, and social support are of concern to rapidly ageing communities. Understanding how the migration trends of the $65+$ population compare to movements made by the rest of the population can assist in planning for future growth.
\end{abstract}

\section{Aim}

The aim of the paper is to understand how the migration patterns of the $65+$ population in Australia have changed over the past forty years in comparison to the total population.

\section{Data and methods}

Five-year interval census migration data were used to examine the migration flows of the 65+ population between 1976 and 2016. A range of metrics was used to measure the level or intensity of internal migration and its impact on the redistribution of the population at the national level. Regional net migration rates were then used to compare net gains and losses between regions and track changes over time in the direction of flows across the Australian settlement system.

\section{Results}

The propensity to migrate declined over the forty years for all ages but proportionally less for the over $65+$ group. Gains in the $65+$ population were spread across a range of middle-density regions with losses from the most urban and remote areas. The migration patterns observed in the total population were less spatially consistent, with periods of gain in some remote regions.

\section{Conclusions}

The system-wide metrics showed an overall decline in migration propensity between regions and changes in the redistributive impact of migration by age. The net migration maps and scatterplots revealed large changes in the regional growth and decline of the $65+$ population as new destinations emerged in regional Victoria and New South Wales.

\section{Key words}

Migration, ageing, 65+, counter-urbanisation, Australia. 


\section{Introduction}

There has been little overall change in the spatial distribution of Australia's population over the past forty years with the majority of people living in urban centres along the coast. Growth is concentrated in the urban periphery, high-amenity regions on the east and southwest coasts, resource-rich areas, and regional centres supported by tourism, while corresponding decline occurs in the wheat-sheep belt, pastoral areas, and former mining towns (Hugo 2013). As regional variations in fertility and mortality are too small to contribute significantly to demographic change in these regions (Jackson \& Felmingham 2002), shifts in the volume and composition of inflows and outflows are behind the changing age structure of regions in Australia (Hugo 2013; McManus \& Pritchard 2000).

Divergence in the age structure of urban and rural Australia has been attributed to increased outmigration of young people from rural areas to pursue education and employment opportunities (Davies 2008), while in-migrants to non-metropolitan Australia tend to be older and attracted to selected wellserviced and amenity-rich communities (Davies \& James 2011). Regularities in age-specific migration rates are well-established (Rogers \& Castro 1981) and while migration research has tended to focus on the movements of the working age population, there are two distinct peaks in the migration propensity at older ages (Rogers 1988), associated with different spatial patterns (Conway \& Houtenville 2003). Newly retired migrants are typically motivated by a desire for the social opportunities and recreational activities offered by high-amenity coastal and hinterland regions adjacent to metropolitan regions (Argent, Smailes \& Griffin 2007; Davies \& James 2011). Conversely, the oldest migrants are often drawn by necessity to the healthcare and assisted living facilities offered by regional centres and metropolitan areas.

In a rapidly ageing society, the demand for amenity, social support, and health and aged care facilities are of growing concern (Kim et al. 2003), and the regional differences in migration flows have increasingly significant socioeconomic, political, and developmental implications (Jackson \& Felmingham 2002; Tonts \& Greive 2002). As understanding the past trends of elderly migration can assist in predicting and planning for future growth, the aim of this paper is to understand how the impact of migration for older Australians has changed over the past forty years in comparison to the total population. To achieve this aim, this paper first establishes the national-level intensity, effectiveness, and impact of migration for each of the eight census periods from 1976-81 to 2011-16. The paper then maps the impact of these moves at the regional level to identify which regions are experiencing gains and losses. Finally, the paper speculates on possible explanations for the observed trends.

\section{Data}

This paper draws on data from the quinquennial Australian Census of Population and Housing administered by the Australian Bureau of Statistics (ABS), covering eight census periods from 1976-81 to 2011-16. The analysis relies on the retrospective "place of usual residence five years ago" question to determine patterns of internal mobility and therefore omits return and repeat moves made during this five-year period. Migrants who die or emigrate during the inter-censal period, 
immigrants who moved prior to the five-year period, and those aged between 0-4 at the time of the census are not counted.

To accommodate changes to administrative spatial boundaries over the study period, the migration flows are organised into 69 temporally-consistent regions (Figure 1). These regions are based on the statistical divisions defined by the ABS: Statistical Local Areas (SLA) for 1976 to 2006 (Bell et al. 1999; Rees et al. 2000), and Statistical Areas Level 2 (SA2) for 2011 and 2016. These data are held by the Queensland Centre for Population Research and can be made available to researchers on request.

It should be noted that only moves made between regions are counted for the purposes of this analysis. A high degree of metropolitan primacy in the Australian settlement system means that regions outside of the state capitals can cover very large areas, resulting in unequal sizes of the spatial units of analysis. This unique geography means that while intra-region moves are often local or short-distance in smaller regions, in larger regions these moves may involve a significant distance as the spatial units may encompass a large range of settlement types.

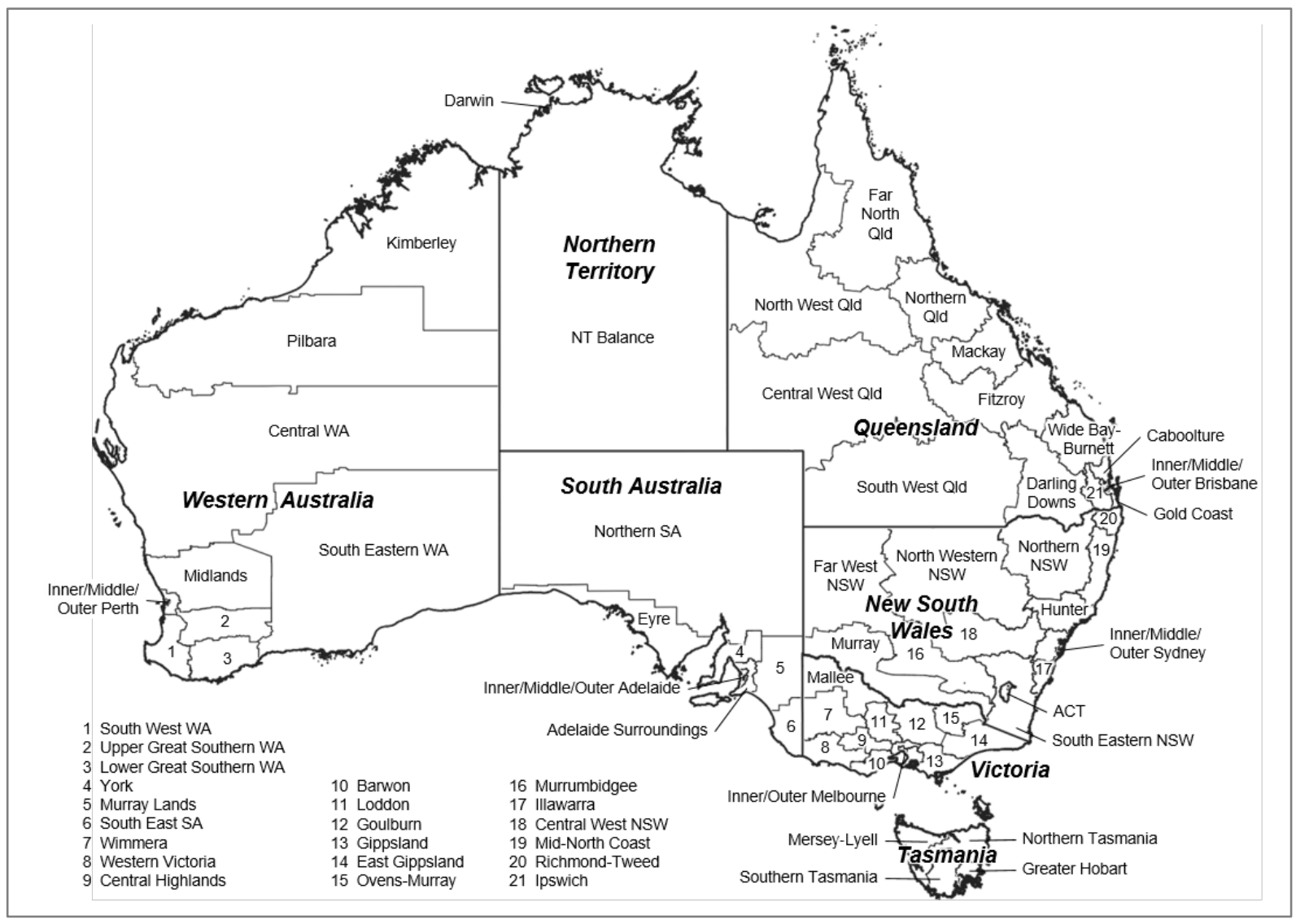

Figure 1: The 69 temporally consistent Australian regions

Source: ABS spatial data, created by author

\section{Methods}

As migration is a multidimensional process, three metrics are used to measure the intensity, effectiveness and impact of the migration system (Bell et al. 2002). Each metric is calculated for the total population, those aged 0-64, and those aged 65+. 
The first metric captures the overall volume of movement that occurs within the population. Intensity is expressed using the crude migration index (CMI) which measures the number of migrants $(M)$ as a percentage of the population at risk $(P)$ of moving.

$C M I=(M / P) \times 100$

The effect of migration on population distributions is not just a function of volume but is related to asymmetry of the migration system or the extent to which migration flows are offset by counter flows. The effectiveness of migration in redistributing the population is measured using the migration effectiveness index (MEI) (Shryock \& Siegel 1975). The MEI is calculated as the absolute value of net migration $\left(D_{i}-O_{i}\right)$ summed across all regions divided by the sum of inflows and outflows for all regions $\left(D_{i}+O_{i}\right)$ (Morrison, Bryan \& Swanson 2004; Plane \& Rogerson 1991). The MEl is reported as a value between 0 and 100 with higher values indicating greater effectiveness.

$M E I=\left(\sum_{i}\left|D_{i}-O_{i}\right| / \sum_{i} D_{i}+O_{i}\right) \times 100$

Intensity and effectiveness together drive the overall impact of migration on the settlement system and the complexity of this relationship can be computed using the aggregate net migration rate (ANMR). The ANMR is used to summarise the system-wide impact resulting from the net balance of inter-regional flows (Bell et al. 2002). The ANMR is expressed as a percentage of half the absolute value of net migration summed across all regions over the population at risk of each group.

$A N M R=\left(0.5 \times \sum_{i}\left|D_{i}-O_{i}\right| / \sum_{i} P_{i}\right) \times 100$

As national-level metrics obscure changes in the composition of regions, the net migration rates (NMR) for each of the 69 regions are mapped to identify spatial patterns in the attractiveness of destinations. The NMR is calculated as the balance of inflows and outflows $\left(D_{i j}-O_{j i}\right)$ for each region $i$ divided by the region's population at risk $\left(P_{i}\right)$.

$N M R=\left(\sum_{i} \sum_{j \neq i}\left(D_{i j}-O_{j i}\right)^{2} / P_{i}\right) \times 100$

Finally, to identify the dominant direction of migration flows across the urban hierarchy, this paper modifies the approach used by Rees et al. (2017). Net migration rates for regions are plotted against population density which is used as a proxy for the degree of urbanisation of a region. This measure accommodates changes in the classification of urban and rural areas within Australia over time. The relationship between net migration rates and population density is estimated using a second-degree polynomial.

\section{Results}

Between 1981 and 2016 the number of people aged 65+ in Australia increased from 1.35 million (9\% of the total population) to 3.26 million (14\%) (Figure 2a). Despite the unprecedented absolute and relative growth of this age group, the number of moves did not increase at the same rate, resulting in a decline in migration intensity for the $65+$ group from $9 \%$ in 1976-81 to 7\% in 2011-16 (Figure 2b). The largest drop occurred in 2006-11 when the migration intensity fell $1.2 \%$, compared to an average decline of $0.3 \%$ for each census period. Overall, migration intensity declined slowly for the $65+$ 
population, dropping only two per cent over forty years. In comparison, the migration intensity of the $0-64$ population declined five percentage points from $17 \%$ to $12 \%$ over the same time period, while the migration intensity of the total population declined four percentage points from $16 \%$ to $12 \%$.

(a)

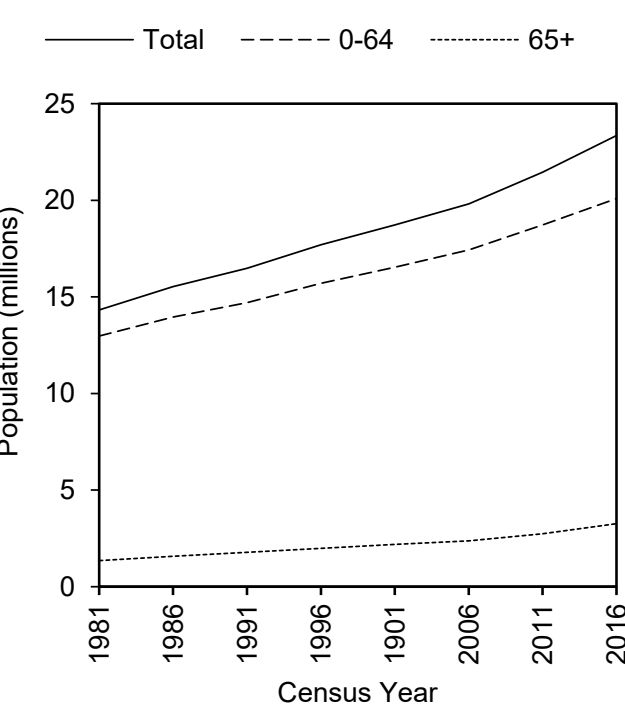

(c)
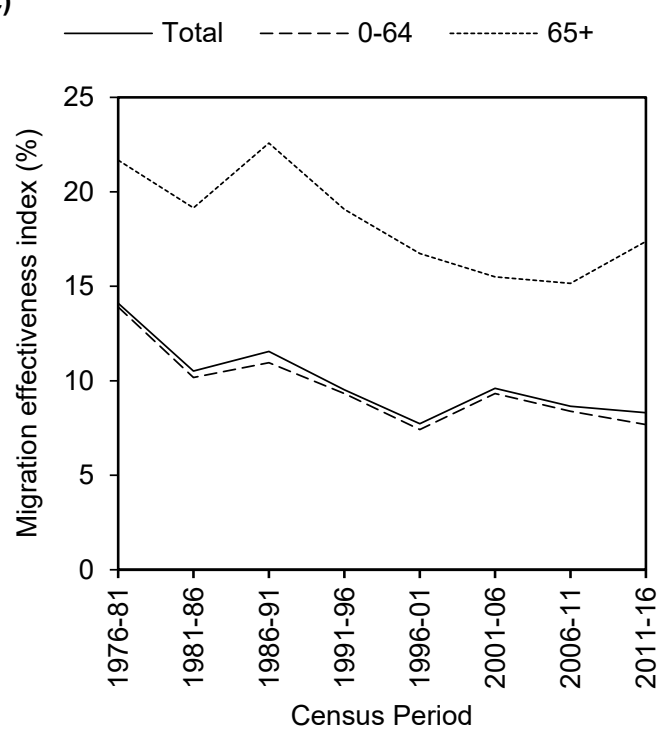

(b)

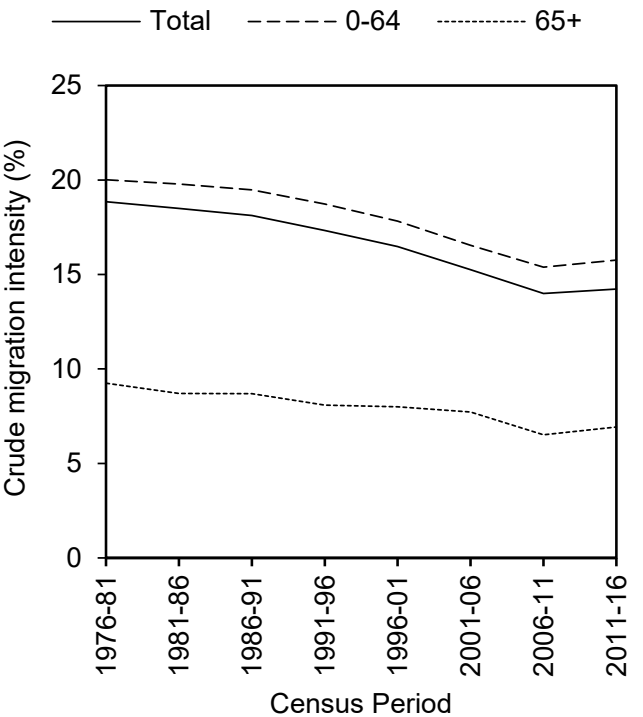

(d)
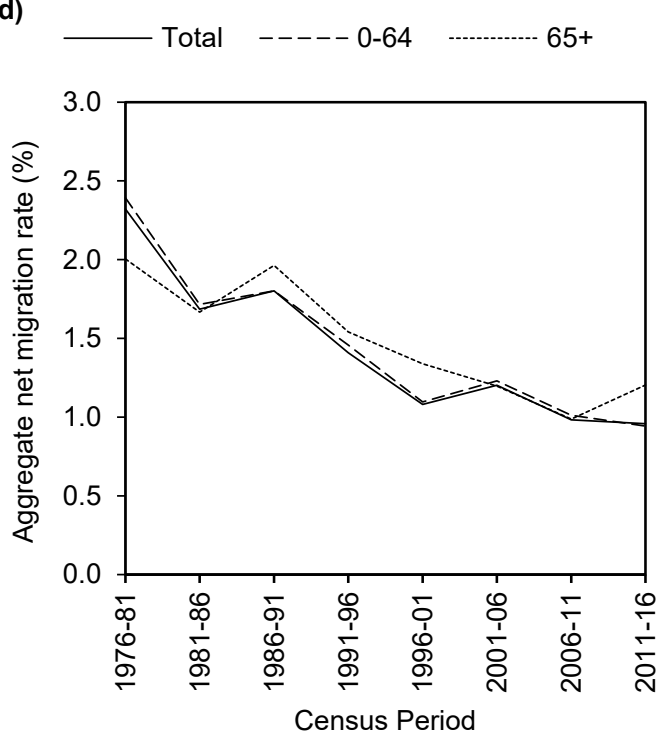

Figure 2: Comparison of (a) population growth, (b) crude migration intensity; (c) migration effectiveness index; and (d) aggregate net migration rate for the total population, those aged 0-64, and those aged over 65 in Australia, 1976-81 to 2011-16

Source: ABS census data, author's calculations

The MEl for the $65+$ group was higher than that recorded by both the $0-64$ group and the total population, meaning that migration was more effective at redistributing those aged $65+$ than the rest of the population. However, the trend was not linear for either age group as the decline was interrupted by periods where migration became more effective at redistributing the population. An initial fluctuation in migration effectiveness for the 65+ group between 1976-81 and 1986-91 was followed by a sustained decline from a maximum of $23 \%$ in $1986-91$ to a minimum of $15 \%$ in $2006-11$ (Figure 2c), before a final increase to $17 \%$ in 2011-16. Migration became less effective at 
redistributing the total population and the 0-64 age group over time, with the MEI of both declining from a maximum of $14 \%$ in $1976-81$ to $8 \%$ in $2011-16$. While the overall pattern of decline was similar across the three groups, the direction of the MEls diverged in the final census period, with the $65+$ group experiencing an increase while the total population and 0-64 group continued to decline.

The ANMR for all three groups exhibited a similar overall decline (Figure 2d); however, while the impact the 0-64 and total groups was virtually identical, the 65+ group had a slightly different trajectory. The highest impact for the $65+$ group occurred in 1976-81, where $2 \%$ of the population was redistributed through migration. While the 0-64 age group and total population initially had a greater impact on the redistribution of the population, the impact of the $65+$ group was greater between 1986 and 2006. All three groups declined to a low of 1\% in 2006-11, though while the impact of the 0-64 and total populations continued to decline, the $65+$ group rose to $1.2 \%$ in 2011-16.

These results illuminate the relationship between the number of migrants and the effectiveness of migration in redistributing the population. Despite the lower volume of migrants in the $65+$ group, the higher effectiveness of this group meant that the overall impact on regional settlement patterns was relatively similar to that of the total population. Conversely, the impact of the 0-64 population was driven by the greater number of migrants.

The impact of internal migration has not been uniform across the settlement system. The pattern of net gains and losses of the $65+$ group were spatially bifurcated with net gains along the east, south, and southwest coasts, and pronounced net loss in the remote regions of each state in all census periods (Figure 3). Movements were initially highly directed towards the amenity-rich regions on the northern coast of New South Wales and southeast Queensland coast receiving high net gains between 1976-81 and 1991-96; however, the intensity of these gains declined over time. The suburban peripheries of Brisbane, Adelaide, and Perth declined further, changing from net gains to net losses between 2001-06 and 2006-11.

Concurrently, inland New South Wales and Victoria flipped progressively over time from net loss to net gain, suggesting a pattern of counter-urbanisation away from the traditional retirement destinations and towards regional centres adjacent to the capital centres. Notably, inner Sydney, Brisbane, Melbourne, and Perth also experienced net losses. More remote regions in each state experienced consistent loss with the highest net losses generally from resource-rich regions of Western Australia and western Queensland.

The broad pattern of net migration for the 0-64 age group (Figure 4) and total population (Figure 5) was similar to that of the $65+$ group, with gains along the east, south, and southwest coasts, and widespread losses in remote inland regions. However, there were also additional gains in key outback resource regions in 1976-81, 1981-86, 2006-11, and 2011-16, and gain in southeast inland regions was not as temporally consistent or spatially extensive as seen in the $65+$ group.

Plotting the net migration rate against the population density for each region reveals a broad trend of net gain in moderately densely populated regions and corresponding losses in high- and low- 


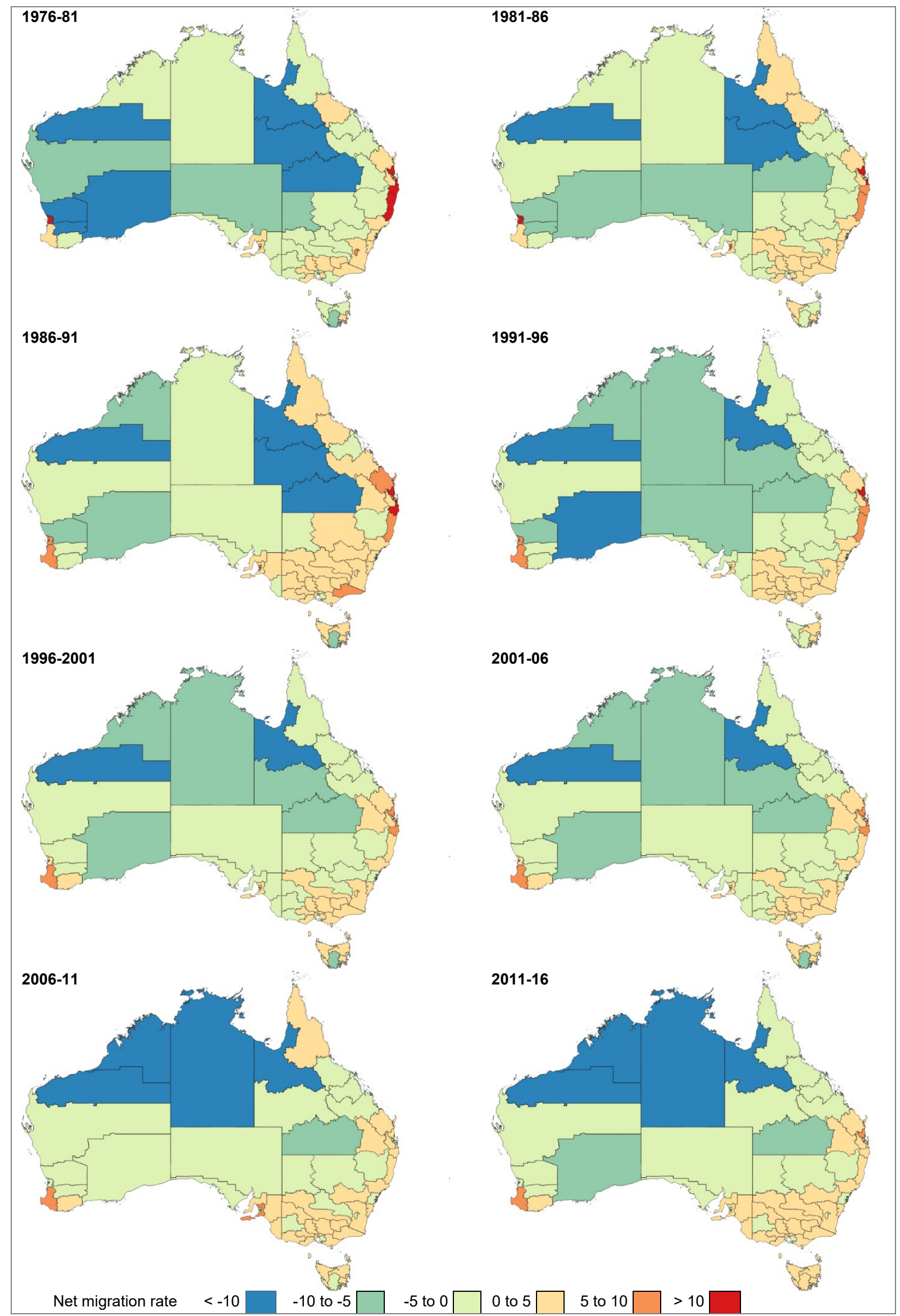

Figure 3: Net migration rate of the 65+ population for regions in Australia, 1976-81 to 2011-16

Source: ABS census data, author's calculations 


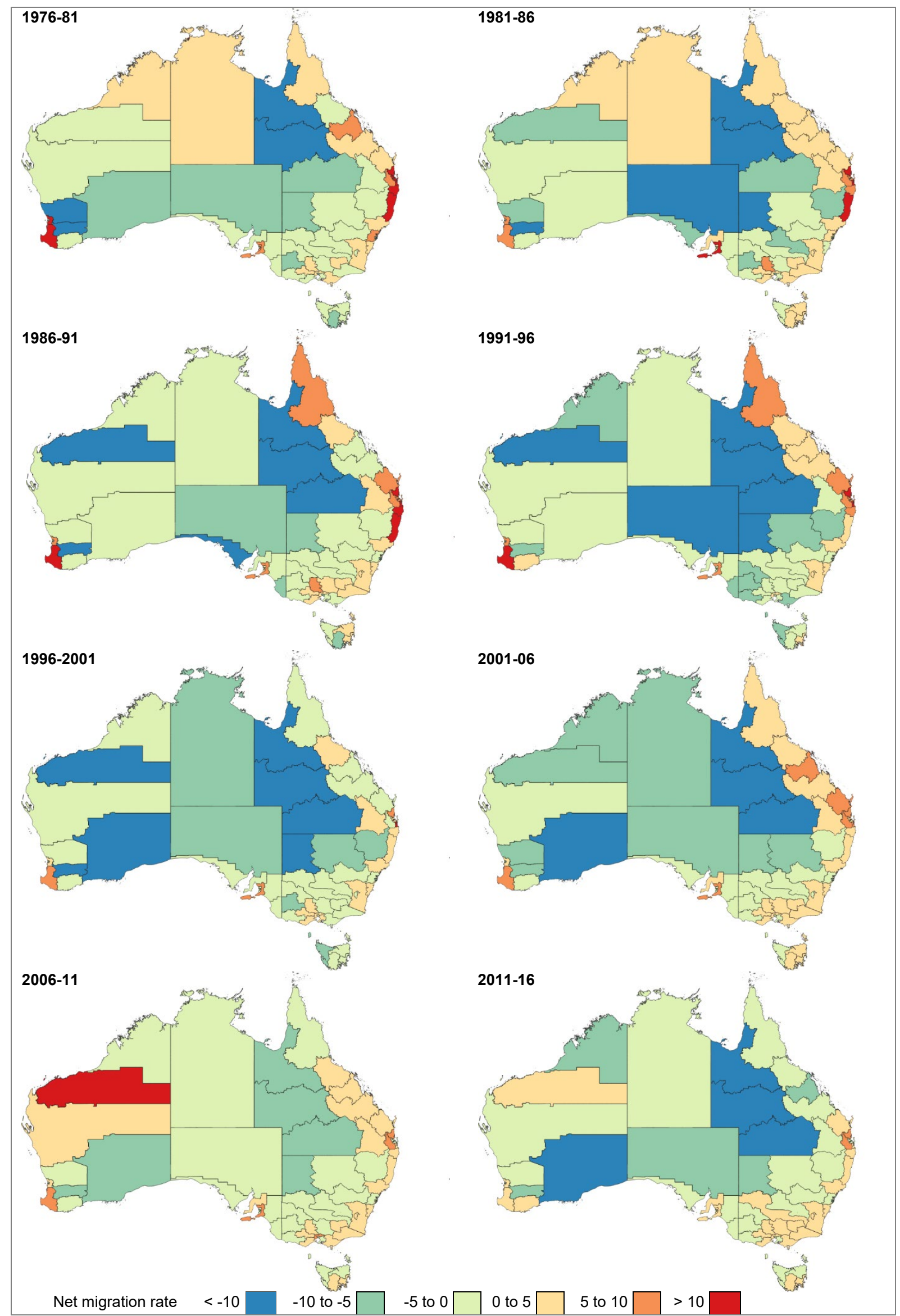

Figure 4: Net migration rate of the 0-64 population for regions in Australia, 1976-81 to 2011-16

Source: ABS census data, author's calculations 


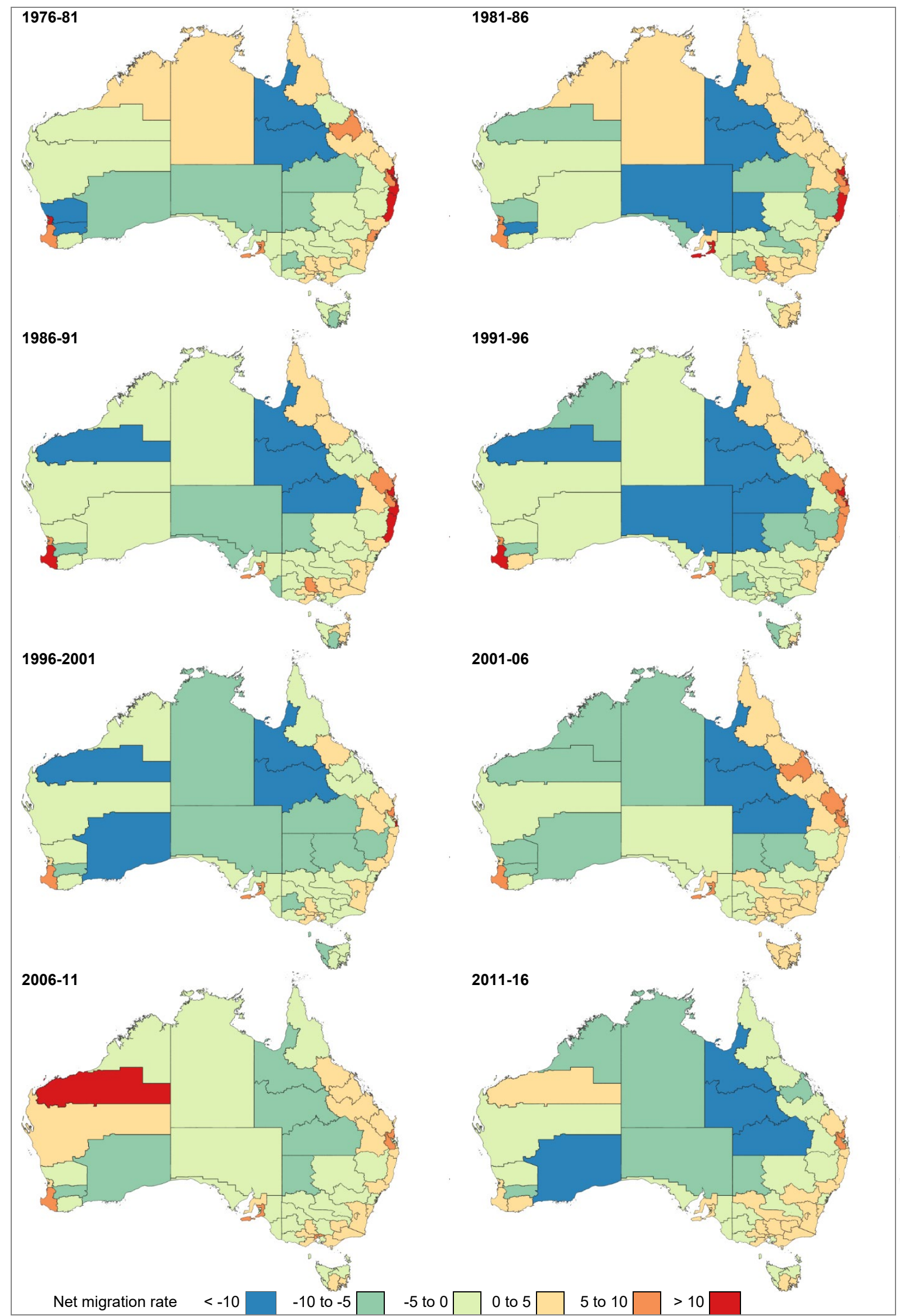

Figure 5: Net migration rate of the total population for regions in Australia, 1976-81 to 2011-16

Source: ABS census data, author's calculations 
density regions for the 65+ population (Figure 6). The strength of the relationship declined slightly between 1976-81 $\left(R^{2}=0.49\right)$ and 2011-16 $\left(R^{2}=0.44\right)$, likely as a result of reduced net gains in middledensity regions and increased net losses in selected low-density regions. Although the presence of this trend is a persistent feature over time, there are notable changes in the magnitude of the gains for regions in southeast Queensland and northern New South Wales, while several suburban capital regions flipped from net gain to net loss. The relationship between net migration and population density was weaker in 1976-81 $\left(R^{2}=0.23\right)$ for the 0-64 age group, likely owing to the higher gains in middle-density areas (Figure 7). This relationship weakened further $\left(R^{2}=0.04\right)$ as a number of middledensity regions experienced net loss in 2011-16.

(a)

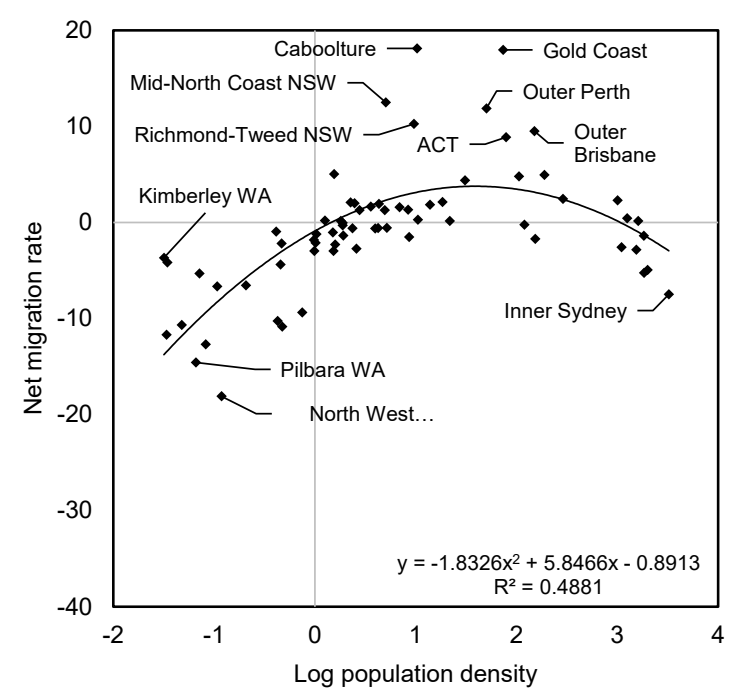

(b)

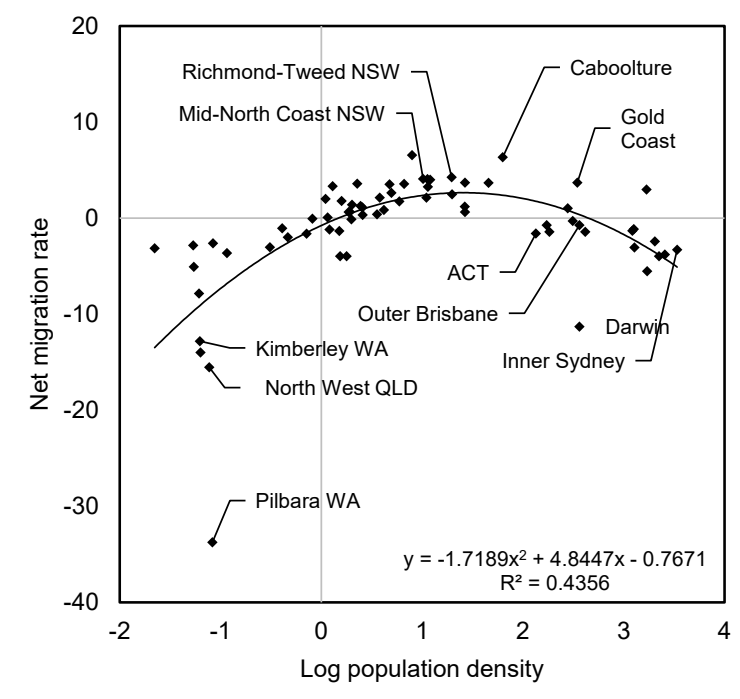

Figure 6: Net migration and population density for the 65+ population in (a) 1976-81 and (b) 2011-16

Source: ABS census data, author's calculations

(a)

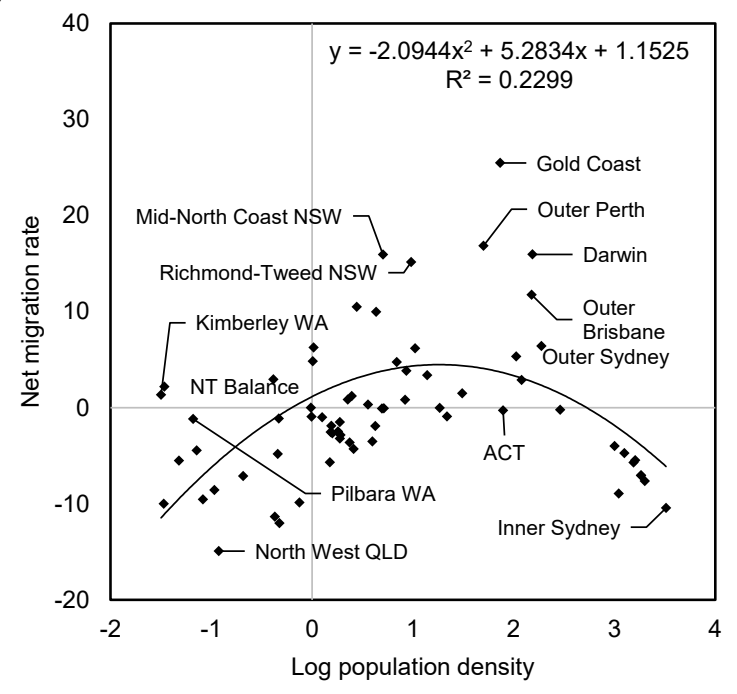

(b)

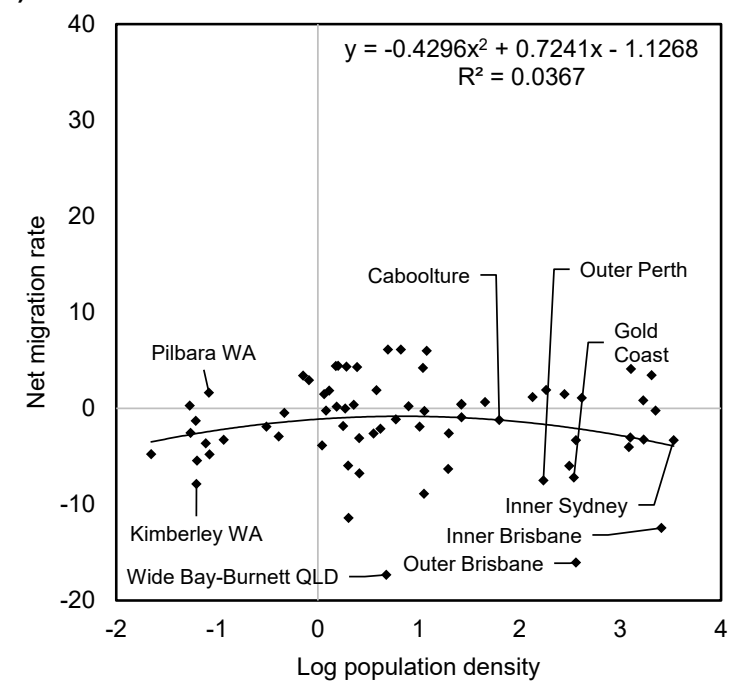

Figure 7: Net migration and population density for the 0-64 population in (a) 1976-81 and (b) 2011-16 
The relationship between net migration of the total population and regional population density (Figure 8) strengthened between 1976-81 $\left(R^{2}=0.24\right)$ and 2011-16 $\left(R^{2}=0.58\right)$, likely as a result of the considerable decline in the magnitude of net gains in middle-density regions. The weak to moderate $R^{2}$ values shown here for both age groups as well as the population overall, indicates that while a relationship exists, there is a substantial amount of variation in the net migration rates that is not explained by regional population density.

(a)

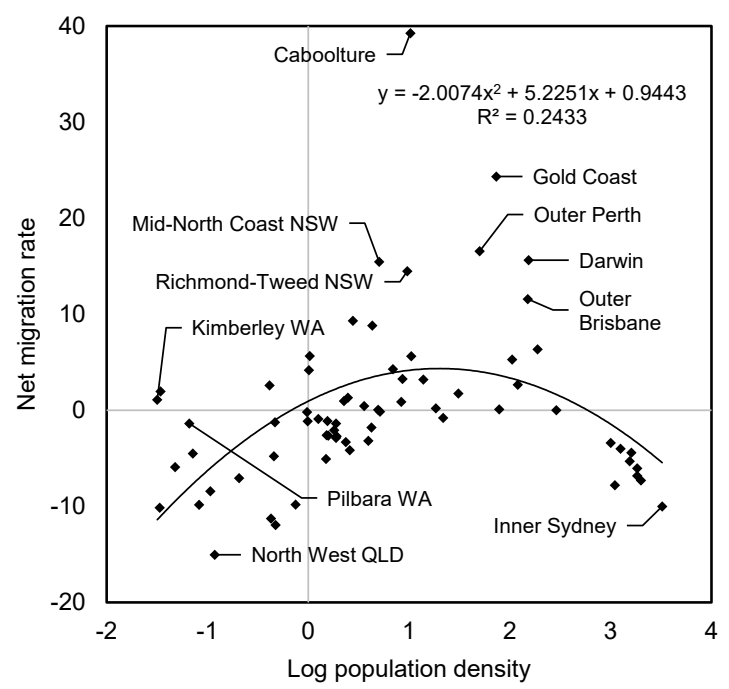

(b)

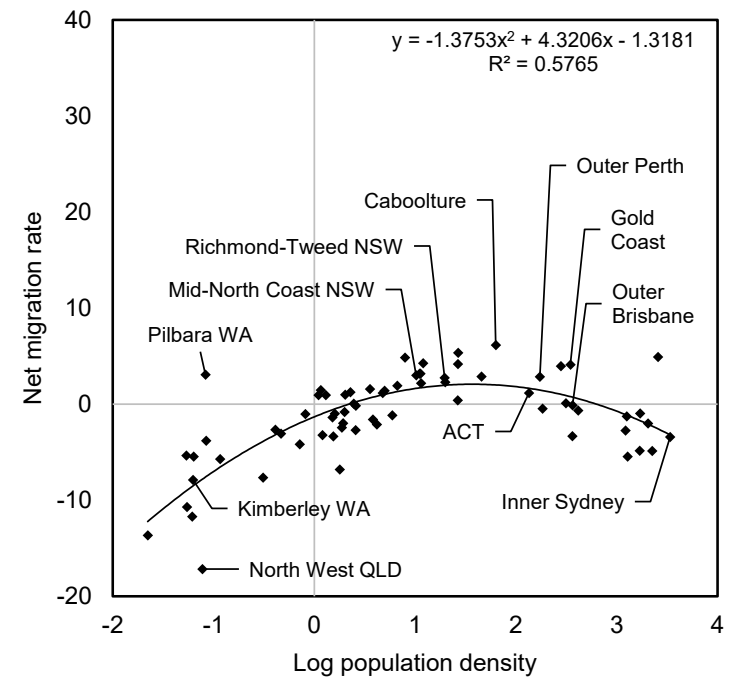

Figure 8: Net migration and population density for the total population in (a) 1976-81 and (b) 2011-16

Source: ABS census data, author's calculations

\section{Discussion}

The aim of this paper was to understand how the migration patterns of Australia's $65+$ population changed over the past forty years in comparison to the 0-64 and total populations. This was achieved by first establishing the system-wide dynamics before investigating the underlying spatial distribution of flows between regions.

The migration intensity of the $65+$ group followed a similar downward trend to that observed in the 0-64 and total populations. Though the share of older people increased, the likelihood of the $65+$ age group moving was approximately half that observed in the 0-64 and total populations and the decline in mobility was less rapid for the 65+ population than the population overall. Conversely, the higher MEl indicates greater asymmetry in the $65+$ migration system with a number of regions gaining population at the expense of losses in others (Shryock \& Siegel 1975). The temporal pattern of increase and decrease was similar to that seen in the 0-64 and total populations until 1996-2001, after which the trends diverged. Notably, the effectiveness of the 65+ group increased in the latest census period after a prolonged period of decline. This could potentially signal a reversal of a longterm trend or simply be an anomaly as seen in 1986-81. For the $65+$ group, the $0-64$ group, and the total population, the overall decline in effectiveness indicates that the migration exerts increasingly less influence in the redistribution of the population over time. Finally, the impact of migration on population redistribution summarised by the ANMR was similar between all three groups despite 
differences in the intensity and effectiveness. This indicates that the asymmetry indicated by the MEI contributes more to the redistribution of the 65+ age group, while the higher $\mathrm{CMI}$ of the 0-64 and total populations indicate that it is the volume of moves that contributes most to the migration impact of these groups. While periods of increase in an otherwise ongoing decline may be attributed to short-term structural economic change (Stillwell et al. 2000), the overall decline can likely be attributed to population ageing, changes to the demographic structure of regions, and the long-term stability of Australia's settlement system (Champion et al. 2018).

Further examining the regions that are gaining and losing reveals a directionality to this shift in the spatial orientation of migration over the forty year period. The 1970s and 1990s were characterised as periods of pronounced counter-urban movement with flows generally directed towards highamenity regions in northern New South Wales (Richmond-Tweed and Mid-North Coast), southeast Queensland (Caboolture and the Gold Coast) and southwest Western Australia (Argent, Smailes \& Griffin 2007). However, emerging trends indicate that regions along the urban periphery and select inland rural regions in Victoria and New South Wales are becoming key destinations for the 65+ group. The scatterplots reveal that moderately dense regions experienced the highest net gain with accompanying losses in very high and low density regions. However, shifts in the regional patterns of gains and losses suggest that the attractiveness of places changes over time so gains may be linked to migrant rather than regional characteristics (Haas \& Serow 1993). For example, moves to the suburban peripheries might be to be near family while increasing gains in less-serviced regional towns - such as those in inland Victoria - may be driven by post-war cohorts returning to their place of birth upon retirement (Jauhiainen 2009).

The spatial pattern of this rural encroachment was not matched by flows from the 0-64 age group, which exhibited a distinct resurgence towards low-density regions in 2001-06 and 2006-11. The accompanying substantial drops in the magnitude of net migration gains for this age group were likely linked to growth of the working-age population in resource-rich outback towns - namely the Pilbara and Central Western Australia - and larger regional bases along the mid-Queensland coast during the mining boom (Robertson, Blackwell \& McFarlane 2017). The lack of an inflection point suggests that the $65+$ population was largely unaffected by these economic-driven flows, though the devaluing of retirement nest eggs during the global financial crisis may have marginally accelerated the decline in migration as people were financially unable to move (Wahlquist 2017).

While increasing affordability of coastal living in the 1970s and 1980s initially attracted retirees to non-metropolitan regions along the east and southwest coasts (Sander 2011), the declining popularity of urban and peri-urban coastal regions with the $65+$ population suggests that they may be being priced out of these regional housing markets. Lifestyle-driven population growth coupled with the slow release of land has reshaped housing and labour markets in these traditional retirement locations (particularly those in southeast Queensland and Northern New South Wales) (Beer 2017; Beer et al. 2011). Understanding housing choices will be more important in the coming years, particularly as key retirement destinations change (Painter \& Lee 2009). Moves by older people are often associated with a change in housing tenure or dwelling size (Clark \& Deurloo 2006; Painter \& Lee 2009), and triggered by changes to personal circumstances or household composition (Abramsson \& Andersson 2015). The desire to continue living independently despite deteriorating 
health will necessitate purpose-built accommodation that is often in short supply in regional areas (Beer et al. 2011).

The age-specific dynamics of gain and loss will have significant consequences for local communities as older people have different service needs and asset levels from the general population. While most regions experienced consistent net gain or loss across all ages and census periods, a number of mostly rural and remote regions along the New South Wales and Victoria border experienced net gain of the 65+ population and the net loss of the 0-64 population during one or more census periods. However, these inflows of the 65+ age group were rarely sufficient to combat the long-term trends of net loss driven by younger age groups. Migration can improve socioeconomic growth in rural areas (Davies 2008), though large flows of older people can also increase the pressure on already limited health care resources (Costello 2009). The concurrent loss of the working-age population may undermine social and economic support systems, further accelerated by the withdrawal of key government services from regional communities (Alston 2004).

While this paper is primarily concerned with understanding the spatial and temporal dynamics of movement, regions must be equally concerned with the increasing proportion of older people who choose to age-in-place. The decline in migration intensity despite increasing numbers of older people suggests a reluctance to relocate, a lack of suitable housing choices, or an inability to meet the costs of moving (Hansen \& Gottschalk 2007). Alternatively, changes in the timing of key life course events such as the trend of working longer may reduce the migration freedom of older people, with a portion of moves simply reflecting late-life job relocations (Day 2019).

\section{Conclusion}

The system-wide metrics revealed an overall decline in the likelihood and impact of between-region moves for the $65+$ population over the past forty years, while comparing change in net migration rates showed shift in the direction and magnitude of moves that differentiate this age group from the 0-64 and total populations. Although the trend of counter-urbanisation established in the 1970s has persisted for the $65+$ group, the destinations have become less focused over time, reflecting the shifting demographic and socioeconomic landscape. These regional communities will need to invest in appropriate amenities, services and infrastructure to meet the needs of the growing 65+ population (Denny 2018). Further stratifying the analysis to distinguish between moves made by those aged 65-74, 75-84 and 85+ and/or including within-region moves would help to explain how the search for amenity or healthcare and social support changes as people age. Extending the analysis to encompass a suite of younger age groups could further illuminate the causal relationships that underscore how migration behaviour changes across the life course (Sander \& Bell 2008) and help us understand how age-differentiated patterns of migration accommodate changes to subnational population age structures.

\section{Key messages}

- Older Australians are consistently less mobile than the overall population.

- The decline in migration propensity between regions is less pronounced for the $65+$ population. 
- Migration towards traditional retirement destinations along the eastern coast has declined in favour of increasing growth in inland regions.

- Emerging destinations need to be prepared to provide appropriate housing, services and infrastructure to accommodate growth of older population.

\section{Acknowledgements}

The author thanks Dr Elin Charles-Edwards, Dr Aude Bernard, and Professor Jonathan Corcoran for providing comments on a draft version of this paper. This research was supported by an Australian Government Research Training Scholarship.

\section{References}

Abramsson M and Andersson E (2015) Changing Preferences with Ageing - Housing Choices and Housing Plans of Older People. Housing, Theory and Society 33(2): 217-241.

Alston M (2004) 'You don't want to be a check-out chick all your life': The out-migration of young people from Australia's small rural towns. The Australian Journal of Social Issues 39(3): 299-313.

Argent N, Smailes PJ and Griffin, T (2007) The amenity complex: Towards a framework for analysing and predicting the emergence of a multifunctional countryside in Australia. Geographical Research 45(3): 217-232.

Beer A (2017) A housing affordability crisis in regional Australia? Yes, and here's why. The Conversation. https://theconversation.com/a-housing-affordability-crisis-in-regional-australia-yes-and-hereswhy-71808. Accessed on 27 January 2020.

Beer A, Tually S, Rowley S, Haslam McKenzie F, Schlapp J, Birdsall-Jones C and Corunna V (2011) The drivers of supply and demand in Australia's rural and regional centres. Australian Housing and Urban Research Institute, Melbourne.

Champion T, Cooke T and Shuttleworth I (eds.) (2018) Internal Migration in the Developed World: Are We Becoming Less Mobile? London: Routledge.

Bell M, Blake M, Boyle P, Duke-Williams O, Rees P, Stillwell J and Hugo G (2002) Cross-national comparison of internal migration: issues and measures. Journal of the Royal Statistical Society Series A (Statistics in Society) 165(3): 435-464.

Bell M, Rees P, Blake M and Duke-Williams O (1999) An Age-Period-Cohort Database of Inter-Regional Migration in Australia and Britain, 1976-96. University of Adelaide, Adelaide. https://core.ac.uk/download/pdf/51003.pdf. Accessed 17 January 2020.

Clark WA and Deurloo M C (2006) Aging in place and housing over-consumption. Journal of Housing and the Built Environment 21(3): 257-270.

Conway K S and Houtenville A J (2003) Out with the old, in with the old: a closer look at younger versus older elderly migration. Social Science Quarterly 84(2): 309-328.

Costello L (2009) Urban-rural migration: housing availability and affordability. Australian Geographer 40(2): 219-233.

Davies A (2008) Declining Youth In-migration in Rural Western Australia: the Role of Perceptions of Rural Employment and Lifestyle Opportunities. Geographical Research 46(2): 162-171.

Davies A and James A (2011) Geographies of Ageing: Social Processes and the Spatial Unevenness of Population Ageing. London: Routledge.

Day C (2019) House prices post-GFC: More household debt for longer. Economic Analysis and Policy 64: 91-102. 
Denny L (2018) Migration is slowing Australia's rate of ageing, but not necessarily in the regions. The Conversation. https://theconversation.com/migration-is-slowing-australias-rate-of-ageing-butnot-necessarily-in-the-regions-94970. Accessed on 27 January 2020.

Haas W H and Serow W J (1993) Amenity retirement migration process: a model and preliminary evidence. The Gerontologist 33(2): 212-220.

Hansen E B and Gottschalk G (2007) What makes older people consider moving house and what makes them move? Housing, Theory and Society 23(1): 34-54.

Hugo G (2013) The changing demographics of Australia over the last 30 years. Australasian Journal on Ageing 32(S2): 18-27.

Jackson N and Felmingham B (2002) As the population clock winds down: Indicative effects of population ageing in Australia's States and Territories. Journal of Population Research 19(2): 97-117.

Jauhiainen J S (2009) Will the retiring baby boomers return to rural periphery? Journal of Rural Studies 25(1): 25-34.

Kim S, Kim H and Kim W G (2003) Impacts of senior citizens' lifestyle on their choices of elderly housing. Journal of Consumer Marketing 20(3): 210-226.

McManus P and Pritchard B (2000) Geography and the Emergence of Rural and Regional Australia. Australian Geographer 31(3): 383-391.

Morrison P A, Bryan T M and Swanson D A (2004) Internal Migration and Short-Distance Mobility. In: Siegel J S and Swanson D A (eds.) The Methods and Materials of Demography. San Diego: Elsevier Academic Press; 493-521.

Painter $G$ and Lee K (2009) Housing tenure transitions of older households: Life cycle, demographic, and familial factors. Regional Science and Urban Economics 39(6): 749-760.

Plane D A and Rogerson P A (1991) Tracking the baby boom, the baby bust, and the echo generations: how age composition regulates US migration. Professional Geographer 43(4): 416-430.

Rees P, Bell M, Duke-Williams O \& Blake M (2000) Problems and solutions in the measurement of migration intensities: Australia and Britain compared. Population Studies 54(2): 207-222.

Rees $P$, Bell M, Kupiszewski M, Kupiszewska D, Ueffing P, Bernard A, Charles-Edwards E and Stillwell J (2016) The impact of internal migration on population redistribution: an international comparison. Population, Space and Place 23(6): e2036.

Robertson S A, Blackwell B D and McFarlane J A (2017) The viability of remote mining communities: insights from community perceptions and employment impact assessments. Impact Assessment and Project Appraisal 35(4): 310-324.

Rogers A (1988) Age patterns of elderly migration: an international comparison. Demography 25(3): 355370.

Rogers A and Castro L J (1981) Model Migration Schedules. International Institute for Applied Systems Analysis, Laxenburg, Austria.

Sander N (2011) Retirement Migration of the Baby Boomers in Australia: Beach, Bush or Busted? PhD Thesis, The University of Queensland, Australia.

Sander N and Bell M (2008) Migration and the life course: Does retirement trigger interregional moves? Paper presented to European Population Conference, Barcelona, Spain, 9-12 July.

Shryock H S and Siegel J S (1975) The Methods and Materials of Demography. US Bureau of the Census, Washington DC.

Stillwell J, Bell M, Blake M, Duke-Williams O and Rees P (2000) Net migration and migration effectiveness: A comparison between Australia and the United Kingdom, 1976-96 Part 1: total migration patterns. Journal of the Australian Population Association 17(1): 17-38.

Tonts $M$ and Greive S (2002) Commodification and Creative Destruction in the Australian Rural Landscape: The Case of Bridgetown, Western Australia. Australian Geographical Studies 20(1): 58-70. 
Wahlquist C (2017) 'They've lost the lot': how the Australian mining boom blew up in property owners' faces. https://www.theguardian.com/australia-news/2017/may/12/theyve-lost-the-lot-how-theaustralian-mining-boom-blew-up-in-property-owners-faces. Accessed on 27 January 2020. 